\title{
Hubungan Stigma Gangguan Jiwa dengan Perilaku Masyarakat Pada Orang dengan Gangguan Jiwa di Wilayah Kerja Puskesmas Karya Wanita Pekanbaru
}

\author{
Usraleli $^{1}$, Dedek Fitriana ${ }^{2}$, Magdalena ${ }^{3}$, Melly $^{4}$, Idayanti ${ }^{5}$ \\ 1,3,4,5 Dosen Program Studi Keperawatan Poltekkes Kemenkes Riau \\ ${ }^{2}$ Mahasiswa Program Studi DIV Keperawatan Poltekkes Kemenkes Riau \\ Correspondence email: usraleli@pkr.ac.id
}

\begin{abstract}
Abstrak. Stigma merupakan salah satu faktor penghambat dalam penyembuhan penderita gangguan jiwa. Banyak masyarakat bersikap tidak baik pada penderita gangguan jiwa dan masyarakat tidak begitu menghiraukan penderita gangguan jiwa. Pemahaman masyarakat mengenai gangguan jiwa sangatlah minim, hal ini menyebabkan penderita mendapatkan sikap yang tidak menyenangkan dari masyarakat dan dari keluargasendiri. Tujuannya untuk mengetahui hubungan stigma gangguan jiwa dengan perilaku masyarakat pada Orang Dengan Gangguan Jiwa (ODGJ)di wilayah kerja Puskesmas Karya Wanita RW 07 Pekanbaru Tahun 2019. Desain penelitian ini adalah deskriptif analitik dengan pendekatan cross sectional dengan jumlah sampel 68 KK responden dengan kriteria sampel yang telah ditetapkan. Instrumen pada penelitian ini adalah kuesioner. Hasil penelitian ini adanya hubungan yang signifikan antara stigma gangguan jiwa dengan perilaku masyarakat pada ODGJ dalam pengetahuan dan sikap masyarakat. Pengetahuan erat kaitanya dengan stigma terhadap ODGJ ( $\rho$ value $=0,013$ dan OR $=0,067$ ). Artiya masyarakat yang memiliki stigma gangguan jiwa yang negatif mempunyai peluang 0,067 kali untuk mempunyai pengetahuan buruk pada ODGJ. Sikap erat kaitanya dengan stigma terhadap ODGJ ( $p$ value $=0,017$ dan $O R=9,2$ ). Artinyamasyarakat yang memiliki stigma gangguan jiwa negatif mempunyai peluang 9,2 kali untuk mempunyai sikap buruk pada ODGJ. Disimpulkan bahwa ada hubungan yang signifikan antara stigma gangguan jiwa dengan perilaku masyarakat pada orang dengan gangguan jiwa di wilayah kerja Puskesmas Karya Wanita RW 07 Pekanbaru Tahun 2019. Disarankan kepada pihak puskesmas untuk meningkatkan sosialisasi mengenai sikap dan penanganan awal ganggun jiwa kepada masyarakat.
\end{abstract}

Kata kunci: Gangguan jiwa; pengetahuan; sikap; stigma

\begin{abstract}
Stigma is one of the inhibiting factors in healing people with mental disorders. Many people do not behave well in people with mental disorders and the public does not care about people with mental disorders. Community understanding of mental disorders is very minimal, this causes sufferers to get unpleasant attitudes from the community and from their own families. The aim was to find out the relationship between the stigma of mental disorders and community behavior in people with mental disorders (ODGJ) in the work area of KaryaWanita Community Health Center RW 07 Pekanbaru in 2019. The design of this study was descriptive analytic withaapproach cross sectional with a sample of 68 respondents with criteria that were has been established. The instrument in this study was a questionnaire. The results of this study have a significant relationship between the stigma of mental disorders and community behavior in ODGJ in people's knowledge and attitudes. Knowledge is closely related to stigma towards ODGJ ( $\rho$ value $=0.013$ and $O R=0.067$ ). The meaning of the community that has a negative stigma of mental disorder has a chance of 0.067 times to have bad knowledge on ODGJ. The attitude is closely related to stigma towards ODGJ ( $p$ value $=0.017$ and $O R=9.2$ ). That meanspeople who have the stigma of negative mental disorder have a chance 9.2 times to have a bad attitude towards ODGJ. It was concluded that there was a significant relationship between the stigma of mental disorders and community behavior in people with mental disorders in the work area of Karya Wanita RW 07 Pekanbaru in 2019. It was recommended to the puskesmas to improve socialization regarding the attitude and initial handling of mental disorders to the community.
\end{abstract}

Keywords: Mental disorders; knowledge; attitude; stigma

\section{PENDAHULUAN}

Kesehatan jiwa adalah kondisi dimana seorang individu dapat berkembang secara fisik, mental, spiritual, dan sosial sehingga individu tersebut menyadari kemampuan sendiri, dapat mengatasi tekanan, dapat bekerja secara produktif, dan mampu memberikan kontribusi untuk komunitasnya. Keadaan seseorang dikatakan sehat jiwa apabila mampu mengendalikan diri dalam menghadapi stresor di lingkungan sekitar dengan selalu berpikir positif dalam keselarasan tanpa adanya tekanan fisik dan psikologis, baik secara internal maupun eksternal yang mengarah pada kestabilan emosionaal. Kondisi perkembangan yang tidak sesuai pada individu disebut gangguan jiwa (UU No.18 tahun 2014).

Gangguan jiwa adalah gangguan otak yang ditandai oleh terganggunya emosi, proses berpikir, perilaku, dan persepsi (penangkapan panca indera). Gangguan jiwa ini menimbulkan stres dan penderitaan bagi penderita dan keluarganya. Gangguan emosi adalah suatu pengalaman yang sadar dan memberikan pengaruh pada aktivitas tubuh serta menghasilkan sensasi organik dan kinetis. Emosi yang tidak terkontrol sangat mempengaruhi aktivitas seperti tidak dapat berfikir 
secara positif, pandangan yang negatif terhadap semua orang dan perilaku yang tidak terkontrol. Gangguan jiwa tersebut dapat menyerang setiap orang tanpa mengenal usia, ras, agama, maupun status sosial-ekonomi (Sutejo, 2017).

\section{World Health Organization (WHO,2016)} menunjukkan masalah gangguan jiwa di seluruh dunia sudah menjadi masalah yang sangat seriuspaling tidak ada 1 dari 4 orang di dunia mengalami masalah mental, diperkirakan ada sekitar 450 juta orang di dunia yang mengalami gangguan kesehatan jiwaterdapat sekitar 35 juta orang terkena depresi, 60 juta orang terkena bipolar, 21 juta terkena skizofrenia, serta 47,5 juta terkena dimensia sementara di Indonesia prevalensi ganggunan mental emosional yang ditunjukkan dengan gejala-gejala depresi dan kecemasan untuk usia 15 tahun ke atas mencapai sekitar 14 juta orang atau 6\% jumlah penduduk Indonesia, seperti skizofrenia mencapai sekitar 400.000 orang atau sebanyak 1,7 per 1.000 penduduk (Riskesdas, 2013).

Di Provinsi Riau merujuk pada riset di tahun 2013 lalu, menunjukkan potensi Orang Dengan Gangguan Jiwa (ODGJ) di Riau 0,9/1.000. Artinya dari 1.000 orang berpotensi mengalami gangguan jiwa 0,9 orang. Sementara berdasarkan data tahun 2016 di Riau mencapai 5.495 orang. Pada tahun 2017 jumlah Orang Dengan Gangguan Jiwa yang tersebar di seluruh kabupaten/kota di Riau mencapai 367 orang Sedangkan angka kejadian di kota Pekanbaru di RSJ Tampan 2017 mencapai 1.887 orang dengan gangguan jiwa, pada wilayah kerja puskesmas karya wanita kota pekanbaru adalah sebanyak 52 orang dengan gangguan jiwa yang terdata dipuskesmas (Dinkes, 2018).

Gangguan jiwa menimbulkan kerugian ekonomi mencapai $\mathrm{Rp} 20$ triliun, akibat hilangnya produktivitas, beban ekonomi dan biaya perawatan kesehatan yang harus ditanggung keluarga dan negara. Klien gangguan jiwa tidak hanya membutuhkan dukungan ekonomi saja tetapi juga memerlukan sistem dukungan sosial yang mencakup dukungan emosional, informasional, instrumental dan penilaian/penghargaan untuk menjalani program pemulihan (recovery) dan menghadapi stigma di masyarakat ( Asmedi, 2012 dalam Rinawati, 2017).

Menurut KBBI stigma adalah ciri negatif yang menempel pada pribadi seseorang karena pengaruh lingkungannya. Stigma adalah bentuk prasangka (prejudice) yang mendiskreditkan atau menolak seseorang atau kelompok karena mereka dianggap berbeda dengan diri kita atau kebanyakan orang. Stigma berhubungan dengan kekuasaan dan dominasi di masyarakat. Pada puncaknya, stigma akan mencipkan ketidaksetaraan sosial. Stigma berurat akar di dalam struktur masyarakat dan juga dalam norma-norma dan nilai-nilai yang mengatur kehidupan seari-hari. Ini menyebabkan beberapa kelompok menjadi kurang dihargai dan merasa malu, sedangkan kelompok lainnya merasa superior (Ardhiyanti dkk,2015) .
Penderita gangguan jiwa sering mendapatkan stigma dan diskriminasi yang lebih besar dari masyarakat disekitarnya dibandingkan individu yang menderita penyakit medis lainnya. Tidak hanya menimbulkan konsekuensi negatif terhadap penderitanya tetapi juga bagi anggota keluarga, meliputi dikatakan orang gila, sikap-sikap penolakan, penyangkalan, dan disisihkan maupun pandangan negatif. Pandangan masyarakat kepada orang gangguan jiwa berdampak pada orang dengan gangguan jiwa tersebut, pandangan tersebut dapat berupa pandangan negatif maupun positif. Pandangan negatif dapat berdampak buruk pada orang dengan gangguaan jiwa yang akan menyebabkan lama proses penyembuhan pada orang gangguan jiwa tersebut. Dalam kondisi ini masyarakat seharusnya berperan sebangai salah satu sistem pendukung pada orang gangguan jiwa. Penderita gangguan jiwa mempunyai risiko tinggi terhadap pelanggaran hak asasi manusia. Mereka sering sekali disebut sebagai orang gila (insanity atau madness). Perlakuan ini disebabkan karena ketidaktahuan atau pengertian yang salah dari keluarga atau anggota masyarakat bahkan perawat atau tenaga medis mengenai gangguan jiwa. Gangguan jiwa dapat mempengaruhi fungsi kehidupan seseorang. Aktivitas, kehidupan sosial, ritme pekerjaan, serta hubungan dengan keluarga jadi terganggu karena gejala ansietas, depresi, dan psikosis. Seseorang dengan gangguan jiwa apapun harus segera mendapatkan pengobatan. Keterlambatan pengobatan akan semakin merugikan penderita, keluarga dan masyarakat (Yosep, 2010 dalam Marini Siti, 2017).

Perilaku manusia pada hakikatnya adalah suatu aktivitas dari pada manusia itu sendiri, perilaku juga adalah apa yang dikerjakan oleh organisme tersebut, baik dapat diamati secara langsung atau tidak langsung dan hal ini berarti bahwa perilaku terjadi apabila ada sesuatu yang diperlukan untuk menimbulkan reaksi yakni yang disebut rangsangan, dengan demikian suatu rangsangan tertentu akan menghasilakan reaksi perilaku tertentu. Dalam kehidupan sehari-hari merupakan reaksi yang bersifat emosional terhadap stimulus sosial. Perilaku manusia itu sangat kompleks dan mempunyai ruang lingkup yang sangat luas perilaku memperngaruhi pengetahuan dan sikap seseorang (Notoatmodjo, 2014).

\section{METODE}

Metode ini adalah kuantitatif, jenis penelitian bersifat deskriptif analitik. Penelitian ini mengggunakan pendekatan cross sectional pengumpulan data variabel independen dan variabel dependen diukur atau dikumpulkan dalam waktu bersamaan dan sekaligus (Setiadi, 2013:69). Pada jenis ini variabel independen dan dependen dinilai secara bersamaan pada satu waktu. Tentunya tidak semua subjek penelitian harus diobservasi pada hari atau pada waktu yang sama, akan tetapi baik variabel independen maupun dependent dinilai hanya satu kali saja. Penelitian ini 
menghubungkan stigma gangguan jiwa dengan perilaku pada Orang Dengan Gangguan Jiwa (ODGJ) di wilayah kerja Puskesmas Karya Wanita RW 07 Pekanbaru.

Populasi penelitian ini adalah seluruh masyarakat dilimbungan baru RW 07 Kecamatan Rumbai Pesisir yang berjumlah $216 \mathrm{KK}$. Penderita gangguan jiwa di limbungan baru RW 07 sebanyak 9 orang (1 orang dalam $1 \mathrm{KK}$ ) atau $9 \mathrm{KK}$. Jadi jumlah populasi menjadi 207 responden karena dikurang dengan penderita skizofrenia di limbungan baru tersebut. Untuk menentukan sampel yang akan digunakan dalam penelitian, terdapat berbagai teknik sampling yang digunakan. Dalam pengambilan sampel, peneliti menggunakan purposive sampling yaitu teknik penentuan sampel dengan pertimbangan tertentu yang dikehendaki peneliti (Setiadi, 2013: 112). Berdasarkan perhitungan didapatkan jumlah sampel 68 sampel. Supaya hasil penelitian sesuai dengan kriteria yang diinginkan peneliti, maka dibuat kriteria tertentu. Kriteria sampel dapat berupa kriteria inklusi dan kriteria eksklusi. Kriteria insklusi adalah kriteria atau ciri-ciri yang dipenuhi oleh setiap anggota populasi yang dapat diambil sebagai sampel, sadangkan kriteria ekslusi adalah kriteria atau ciri-ciri yang tidak dipenuhi oleh setiap anggota populasi yang dapat diambil sebagai sampel (Setiadi,2013: 130).

Adapun kriteria inklusi untuk penelitian ini adalah:

1. Masyarakat yang tinggal di Limbungan Baru Kecamatan Rumbai Pesisir

2. Tidak buta huruf dan bisa membaca dan menulis

3. Bisa berkomunikasi dengan baik

4. Bersedia menjadi responden

5. Sehat jasmani dan rohani

6. Masyarakat yang berumur 18 tahun keatas

Adapun kriteria eksklusi untuk penelitian ini adalah:

1. Masyarakat yang tidak berada ditempat saat peneliti melakukan penelitian

2. Masyarakat yang tidak bersedia menjadi responden

3. Masyarakat yang tidak sehat jasmani maupun rohani

4. Masyarakat yang berumur di bawah 18 tahun

Pengumpulan data primer diperoleh melalui wawancara yang menggunakan kuesioner, yang mempunyai dua variabel yaitu: stigma gangguan jiwa dan perilaku masyarakat terhadap penderita gangguan jiwa. Cara mengukur variabel indenpenden yaitu menggunakan kuisioner Community Attitudes Toward The Mentally III dengan jumlah pernyataan sebanyak 24 buah. Dengan menggunakan pengukuran skala Likert untuk pernyataan positif terdapat pada 1,8,9,10,12,13,16,17,19,20,21,22,23 Pilihan jawaban (5) Sangat Setuju (SS), (4) Setuju (S), (3) Ragu-Ragu (RR), untuk pernyataan negatif terdapat pada 2,3,4,5,6,7,11,14,15,18,24 pilihan jawaban (2) Tidak Setuju (TS), (1) Sangat Tidak Setuju (STS).
Sedangkan variabel dependen yaitu perilaku berisi pernyataan-pernyataan terpilih yaitu tentang pengetahuan berdasarkan jawaban Ya dengan kategori baik terdapat pada pernyataan nomor 3,4,5,6,7 dan jawaban Tidak dengan kategori tidak baik terletak pada pernyataan $1,2,8,9,10$. sikap berdasarkan pernyataan positif terdapat pada penyataan nomor 2,3,4,8,11 dengan jawaban (4) Sangat Setuju (SS), (3) setuju (S) dan pernyataan negatif terdapat pada pernyataan nomor 1,5,6,7,9,10 dengan pilihan jawaban (2) Tidak Setuju (TS), (1) Sangat Tidak Setuju (STS). Pengumpulan data yang dilakukan penelitian adalah kuesioner atau angket sesuai dengan tujuan penelitian dan mengacu pada kerangka konsep yang telah dibuat.

\section{HASIL DAN PEMBAHASAN}

Tabel 1. Hubungan Stigma Gangguan Jiwa dengan Pengetahuan Masyarakat Pada Orang Gangguan Jiwa di wilayah kerja Puskesmas KaryaWanita RW 07 Pekanbaru Tahun $2019(\mathrm{~N}=68)$

\begin{tabular}{llllllll}
\hline \multirow{2}{*}{ No } & \multirow{3}{*}{ Stigma } & \multicolumn{4}{c}{ Pengetahuan } & \multirow{2}{*}{ Total } \\
\cline { 3 - 6 } & & Baik & \multicolumn{3}{c}{ Tidak baik } & \multirow{2}{*}{ Total } & $\%$ \\
\cline { 2 - 6 } & & $\mathrm{N}$ & $\%$ & $\mathrm{~N}$ & $\%$ & & \\
\hline 1 & Negatif & 8 & 11.8 & 28 & 41.1 & 36 & 52.9 \\
2 & Positif & 20 & 29.4 & 12 & 17.7 & 32 & 47.1 \\
\hline & Total & 28 & 41.2 & 40 & 58.8 & 68 & 100 \\
\hline
\end{tabular}

Berdasarkan Tabel 1. dapat dilihat bahwa hasil analisa hubungan stigma gangguan jiwa dengan pengetahuan masyarakat pada orang dengan gangguan jiwa di wilayah kerja Puskesmas Karya Wanita RW 07 dari 68 responden diperoleh bahwa stigma negatif dan pengetahuan baik sebanyak 8 responden $(11,8 \%)$, responden dengan stigma positif dan pengetahuan baik sebanyak 20 responden $(29,4 \%)$. Responden dengan stigma positif dan pengetahuan tidak baik sebanyak 12 responden $(17,7 \%)$, responden dengan tingkat stigma negatif dan pengetahuan tidak baik sebanyak 28 responden $(41,1 \%)$.

Hasil uji hubungan tersebut memenuhi syarat untuk uji dengan menggunakan uji chi-squarediperoleh $p$ value 0,013 dimana nilai tersebut lebih kecil dari $\alpha$ $(0,013<0,05)$, sehingga Ha diterima yang artinya ada hubungan yang signifikan antara stigma gangguan jiwa dengan pengetahuan masyarakat pada oarang dengan gangguan jiwa.

Pada stigma gangguan jiwa di Puskesmas Karya Wanita RW 07, hasil analisa diperoleh nilai Odss Ratio sebesar 0,691, artinya masyarakat yang memiliki stigma gangguan jiwa yang negatif mempunyai peluang 0,691 kali untuk mempunyai pengetahuan masyarakat yang tidak baik pada orang gangguan jiwa (ODGJ). 
Usraleli et al, Hubungan Stigma Gangguan Jiwa dengan Perilaku Masyarakat Pada Orang dengan Gangguan Jiwa di Wilayah Kerja Puskesmas Karya Wanita Pekanbaru

Tabel 2. Hubungan Stigma Gangguan Jiwa Terhadap Sikap

Masyarakat Pada Orang dengan Ganguan Jiwa diwilayah kerja Puskesmas Karya Wanita RW 07 Pekanbaru Tahun 2019

\begin{tabular}{|c|c|c|c|c|c|c|c|c|c|}
\hline \multirow{3}{*}{ No } & \multirow{3}{*}{ Stigma } & \multicolumn{4}{|c|}{ Sikap } & & & \multirow{3}{*}{$\begin{array}{l}\mathrm{P} \\
\text { Value }\end{array}$} & \multirow{3}{*}{ OR } \\
\hline & & \multicolumn{2}{|c|}{ Baik } & \multicolumn{2}{|c|}{ Buruk } & \multicolumn{2}{|c|}{ Total } & & \\
\hline & & $\mathrm{N}$ & $\%$ & $\mathrm{~N}$ & $\%$ & $\mathrm{~N}$ & $\%$ & & \\
\hline 1 & Negatif & 10 & 14,7 & 26 & 38,2 & 36 & 52,9 & \multirow{3}{*}{0,033} & \multirow{3}{*}{9,176} \\
\hline 2 & Positif & 14 & 20,6 & 18 & 26,5 & 32 & 47,1 & & \\
\hline & Total & 24 & 35,6 & 44 & 64,7 & 68 & 100 & & \\
\hline
\end{tabular}

Berdasarkan Tabel 2. dapat dilihat bahwa hasil analisa hubungan stigma gangguan jiwa dengan sikap masyarakat pada orang dengan gangguan jiwa di wilayah kerja Puskesmas Karya Wanita RW 07 dengan jumlah 68 responden diperoleh bahwa stigma negatif dengan sikap baik sebanyak 10 responden $(14,7 \%)$, responden dengan stigma positif dengan sikap baik sebanyak 14 responden (20,6\%). Sedangkan responden stigmanegatif dan sikap buruk sebanyak 26 responden $(38,2 \%)$, responden stigma positif dan sikap buruk sebanyak 18 responden $(26,5 \%)$.

Hasil uji hubungan tersebut memenuhi syarat untuk uji dengan menggunakan uji chi-square diperoleh $p$ value 0,033 dimana nilai tersebut lebih kecil dari $\alpha(0,033<0,05)$, sehingga Ha diterima yang artinya ada hubungan yang signifikan anatara stigma gangguan jiwa dengan sikap masyarakat pada oarang dengan gangguan jiwa.

Pada stigama gangguan jiwa di Puskesmas Karya Wanita RW 07, hasil analisa diperoleh nilai Odss Ratio sebesar 9.176 artinya masyarakat yang memiliki stigma gangguan jiwa yang negatif mempunyai peluang 9.176 kali untuk mempunyai sikap masyarakat yang buruk pada ODGJ.

\section{Hubungan Stigma Gangguan Jiwa dengan Pengetahuan Masyarakat di Wilayah Kerja Puskesmas Karya Wanita}

Hasil analisis penelitian didapatkan stigma gangguan jiwa negatif dengan pengetahuan tidak baik sebanyak 28 responden dengan jumlah $41,1 \%$. Berdasarkan uji statistik Chi-Square di dapat $\rho$ value $=$ 0,013 , jika dibandingkan dengan nilai $\alpha=0,05$ maka $\rho$ value $<$ a 0,05 maka ada hubungan antara stigma gangguan jiwa dengan pengetahuan masyarakat pada ODGJ) di wilayah kerja Puskesmas Karya Wanita RW 07. Hasil uji statistik juga didapatkan nilai $\mathrm{OR}=0,691$ artinya masyarakat yang memiliki stigma gangguan jiwa yang negatif mempunyai peluang 0,691 kali untuk mempunyai pengetahuan masyarakat yang tidak baik pada ODGJ.

Stigma negatif dengan pengetahuan yang tidak baik yang dimiliki oleh masyarakat karena banyak masyarakat yang masih memberi lebel negatif kepada ODGJ. Hal ini dikarenakan banyak masyarakat yang mengatakan ODGJ dengan sebutan orang gila karena panggilan itu sudah melekat dari dahulu kala, takut dengan ODGJ, tidak mau bergaul atau mendekti ODGJ maupun keluarganya, ODGJ sebaiknya dimasukkan ke rumah sakit jiwa saja agar lingkungan disekitar aman dari amukan ODGJ yang tiba-tiba, dan masyarakat juga mengatakan belum pernah mendapatkan penyuluhan tentang gangguan jiwa sehingga masyarakat tidak mengetahui tentang gangguan jiwa.

Rendahnya pengetahuan masyarakat mengenai informasi tentang tanda dan gejala gangguan jiwa seharusnya dapat menjadi perhatian dari tenaga kesehatan agar dapat memberikan penyuluhan kepada masyarakat. Pengetahuan masyarakat sangat penting dalam mendasari terbentuknya sikap dalam penerimaan tehadap ODGJ. Pengetahuan tersebut dapat diperoleh secara alami maupun secara terencana yaitu melalui proses pendidikan. Selain pendidikan perlu adanya kesadaran juga dari masyarakat sendiri, sehingga masyarakat memiliki pengetahuan yang baik agar tercipta nya stigma yang positif terhadap ODGJ yang berada disekitar lingkungannya.

Tidak semua masyarakat memiliki stigma yang negatif terhadap penderita gangguan jiwa, ada masyarakat yang memiliki stigma positif dengan penegtahuan yang baik. Hal ini dikarena kan masih ada rasa peduli masyarakat terhadap ODGJ yang berada disekitarnya, masyarakat mengatakan ODGJ memiliki hak sama seperti kita untuk hidup dan dihargai serta dilindungi, peduli dan memerhatikan ODGJ merupakan salah satu proses penyembuhan pada ODGJ tersebut, sebagian masyarakat juga mengatakan suka membaca dan mencari info mengenai gangguan jiwa karena setiap kita memiliki potensi gangguan jiwa yang harus kita pahami untuk diri sendiri maupun untuk orang lain.

Hasil penelitian ini sama dengan penelitian yang dilakukan Arnika Dwi Asti dkk tahun 2016 Tentang Public Stigma Terhadap ODGJ di Kabupaten Kebumen yang menyatakan bahwa salah satu penyebabnya karena rendahnya tingkat pendidikan dan pengetahuan mengenai kesehatan jiwa di masyarakat Desa Rogodono menyebabkan masyarakat memberikan pelabelan, prasangka dan diskriminasi ODGJ. Adanya public stigma menyebabkan ODGJ semakin menderita, mengalami kesulitan untuk sembuh dan rentan mengalami kekambuhan.

\section{Hubungan Stigma Gangguan Jiwa dengan Sikap Masyarakat di Wilayah Kerja Puskesmas Karya Wanita}

Hasil analisis penelitian didapatkan stigma gangguan jiwa negatif dengan sikap buruk sebanyak 26 responden dengan jumlah $38,2 \%$. Berdasarkan uji statistik Chi-Square di peroleh $\rho$ value $=0,033$, jika dibandingkan dengan nilai $\alpha=0,05$ maka $\rho$ value $<\alpha$ 0,05 artinya ada hubungan antara stigma gangguan jiwa dengan sikap masyarakat pada ODGJ di wilayah kerja Puskesmas Karya Wanita RW 07. Hasil uji statistik menunjukkan bahwa $O R=9,176$ artinya masyarakat 
yang memiliki stigma gangguan jiwa negatif mempunyai peluang 9,176 kali untuk mempunyai sikap masyarakat yang buruk pada ODGJ.

Hal ini dikarenakan pegetahuan yang buruk sehingga terciptanya sikap yang buruk terhadap ODGJ. Masyarakat mengatakan tidak begitu menghiraukan penderita gangguan jiwa, masyarakat bersikap acuh tak acuh karena kesibukan masing-masing, dan juga masyarakat memandang itu adalah masalah yang negatif, memalukan serta mengancam, sehingga masyarakat menjauhi ODGJ beserta keluarganya. Masyarakat mengatakan takut dan tidak mau ikut campur dalam urusan tentangganya yang menggalami gangguan jiwa.

Sikap masyarakat yang tiak peduli dikarenakan takut ODGJ tersebut kambuh atau melakukan hal yang membahayakan bagi keluarganya. Masyarakat juga mengatakan ODGJ sangat meresah kan masyarakat karena mereka suka meminta uang atau pun makanan, seharusnya ODGJ tersebut dibawa kerumah sakit jiwa dan tidak berkeliaran diluaran.

Tetapi tidak semua masyarakat di RW 07 memiliki stigma negatif dengan sikap buruk, ada masyarakat yang memiliki stigma positif dengan sikap baik sebanyak hal ini dikarenakan masyarakat peduli dengan tetangga dan merasa kasihan dengan ODGJ maupun keluarga nya. Masyarakat mengatakan jika masalah gangguan jiwa tersebut terjadi kepada kita apakah kita terima diasingkan dan dibenci oleh orang lain dan masalah gangguan jiwa harus diperhatikan dan ditangai dengan seksama dari pihak kesehatan atau puskesmas maupun dari lingkugan masyarakatnya. Stigma positif akan memberikan sikap yang baik kepada ODGJ maupun keluaganya. Sehingga tidak ada lagi lebel negatif yang melekat dimasyarakat kepada ODGJ tersebut.

Penelitian yang dilakukan oleh Yulianti (2016), dengan memperoleh nilai signifikan 0.000 , berarti ada hubungan antara tingkat pendidikan dengan sikap masyarakat terhadap pasien gangguan jiwa.. Penelitian yang dilakukan oleh Wiharjo (2014) juga menyatakan bahwa terdapat faktor lain yang mempengaruhi sikap yaitu stigma masyarakat, dengan hasil $(\mathrm{p})=0,000(\mathrm{p}<$ $0,05)$, artinya hubungan positif yang signifikan antara stigma masyarakat dengan sikap masyarakat terhadap penderita skizofrenia. Perbedaan stigma masyarakat terhadap penderita skizofrenia dipengaruhi oleh beberapa faktor, diantaranya kurangnya informasi.

\section{SIMPULAN}

1. Stigma masyarakat di wilayah kerja Puskesmas Karya Wanita RW 07 Pekanbaru adalah mayoritas negatif sebanyak 36 orang $(52,9 \%)$.

2. Pengetahuan masyarakat di wilayah kerja Puskesmas Karya Wanita RW 07 Pekanbaru adalah mayoritas tidak baik sebanyak 40 orang $(58,8 \%)$.
3. Sikap masyarakat di wilayah kerja Puskesmas Karya Wanita RW 07 Pekanbaru adalah mayoritas baik sebanyak 44 orang $(64,7 \%)$.

4. Ada hubungan stigma gangguan jiwa dengan pengetahuan masyarakat terhadap orang dengan gangguan jiwa di Wilayah Kerja Puskesmas Karya Wanita RW 07 Pekanbaru dengan $p$ value $(0,013)<$ 0,05 artinya hipotesis alternatif $(\mathrm{Ha})$ diterima.

5. Ada hubungan stigma gangguan jiwa dengan sikap masyarakat terhadap orang dengan gangguan jiwa di wilayah kerja Puskesmas Karya Wanita RW 07 Pekanbaru dengan $p$ value $(0,033)<0,05$ yang artinya hipotesis alternatif $(\mathrm{Ha})$ diterima.

\section{Saran}

1. Bagi Puskesmas

Disarankan kepada pihak puskesmas untuk meningkatkan sosialisasi mengenai sikap dan pengetahuan awal gangguan jiwa kepada masyarakat.

2. Bagi Pendidikan Keperawatan

Diharapkan penelitian ini dapat memperkaya keilmuan keperawatan khususnya keperawatan jiwa dan komunitas. Peneliti juga berharap menjadi materi tambahan di institusi pendidikan dan perpustakaan.

3. Bagi Peneliti Selanjutnya

Penelitian ini dapat menjadi data dasar dan referensi bagi peneliti selanjutnya. Perlu dilakukan penelitian lanjutan mengenai tindakan masyarakat terhadap ODGJ.

\section{DAFTAR PUSTAKA}

Ardhiyanti, Yulrina (2015). AIDS pada Asuhan Kebidanan. Yogykarta. CV. Budi Utama.

Dinas Kesehatan Provinsi Riau. Profil Kesehatan Provinsi Riau 2017. Pekanbaru: Dinas Kesehatan Provinsi Riau: 2018

Kementerian Kesehatan RI. (2013). Riset Kesehatan Dasar 2013, Badan Penelitian Dan Pengembangan Kesehatan. Jakarta: Kementerian Kesehatan RI.

Notoatmodjo. (2014). Kesehatan Masyarakat. PT Rineka Cipta. Jakarta: Rineka Cipta.

RSJ Tampan (2017). Laporan akuntabilitas kinerja rumah sakit jiwa Tampan tahun anggaran 2017. Pekanbaru: RM RSJ Tampan. diakses 01 desember 2018. https://www.slideshare.net/JakaCheryl/lakip2017-rsj-tampan-provinsi-riau.

Setiadi. (2013). Konsep dan Praktik Penulisan Riset Keperawatan. Ed.2. Yogyakarta: Graha Ilmu.

Sutejo. (2017). Keperawatan Kesehatan Jiwa. Yogyakarta: PT. Pustaka Baru

Pengertian stigma menurut KBBI. (2014). Di unduh pada tanggal 10 November 2017 di https://kbbi.web.id/stigma.

UU No 18. (2014). Kesehatan Jiwa. di unduh pada tanggal 02 Januari 2019. Di 
Usraleli et al, Hubungan Stigma Gangguan Jiwa dengan Perilaku Masyarakat Pada Orang dengan Gangguan Jiwa di Wilayah Kerja Puskesmas Karya Wanita Pekanbaru

http://ditjenpp.kemenkumham.go.id/arsip/ln/2014/ uu18-2014bt.pdf.

Wiharjo. (2014). Hubungan persepsi dengan sikap masyarakat terhadap penderita skizofrenia di Surakarta. Diperoleh tanggal 1 mei 2019 dari http://eprints.ums.ac.id/31866/9/02.\%20Naskah\% 20Publikasi.pdf

Yulianti. (2016). Hubungan tingkat pendidikan dan tingkat pengetahuan tentang kesehatan jiwa dengan sikap masyarakat terhadap pasien gangguan jiwa di rw xx desa duwet kidul, baturetno, wonogiri. Diperoleh pada tanggal 12 Februari 2018 dari https://ejurnal.akperpantikosala.ac.id/index.php/jik larticle/download/79/53. 